\title{
Eight new universal public health measures
}

Keywords: shut mouth, air in nose, mouth cough, panic, temper, rage, confusion, hygiene, cigarettes, marihuana, inhalants, snorts, street drugs, steroids, squiggles, throat

\section{Best mouth hygiene}

Almost all contagious diseases from Strep Throat to viruses infect through the mouth--especially the gums (In fact, most likely all diseases have something to do with what we inhale or ingest). Basically, a clean mouth means strong gums which means better health. Teeth should be brushed twice a day--morning and bedtime with flossing before each time. Flossing firmly strengthens the gums. Teeth, gums and tongue need brushing, especially the gums which need massaging to stay firm and strong. The vibrating toothbrushes are best and give a 2 minute hygienic cleansing better than any manual brushing. The cost is readily covered by money saved on medications and less than the electronic game gadgets everyone has. Mouth hygiene means not putting garbage into your mouth: Keep hands clean; avoid cigarettes, marihuana, inhalants, snorts, street drugs, or anything unclean. Keep everything about and in your mouth clean and your gums strong. Mouth gargling and rinsing several times a day with a favorite overthe-counter mouthwash and/or occasionally with strong salt water solution (salt water kills most germs) is recommended. Finally, "best breathing" by the nose strengthens the mouth gums also by lessening gum dryness, and the nose is both a barrier and expeller of negative inhalants. (Also, as in 5 infra, topical dental antibiotic rub should be helpful in preventing infections if on steroids or if in a hospital or any where high in infectious agents. In fact, a dab of triple antibiotic ointment in the nose and on teeth at the first sign of a cold might strengthen resistance).

\section{Best breathing}

Make no mistake; there is a "best" way to breath. "Nasal inhalation" is the best way--It is more diaphragmatic requiring less muscle effort and thus more of the inhaled oxygen is used elsewhere in the body. However, "shutting your mouth" is obligatory for efficient and effective "nasal breathing"--laryngeal reflexes open better with "air into the nose" than with "air into the mouth." Mouth closure while breathing prevents dryness of mouth mucous membranes which work best when moist. A dry mouth because of mouth breathing does not protect well. Snoring dries the mouth, so practice sleeping by nasal inhaling and exhaling with shut mouth is essential. Choking basically is the erroneous intermingling of inhaling and swallowing which can be prevented and corrected by nasal breathing. Learn and practice the acronym "SAM": Shut mouth; Air in nose; Mouth cough (if choking or clearing throat) or just exhale (by mouth or preferably nose). The SAM must be practiced--it does not come naturally for most. Learn, practice, and teach the SAM--you will be "best breathing." (By the way, the SAM works as a panic/temper/rage/confusion stopping technique by detachment from the source of emotionality to calmer self-awareness and improved oxygenation--'Just do the SAM and think it through").

\section{Best coughing "Pulmonary hygiene!"}

Coughing is the body's way of expelling something unwanted. To

\author{
Volume 4 Issue I - 2017
}

\author{
Samuel A Nigro \\ Retired, Assistant Clinical Professor Psychiatry, Case Western \\ Reserve University School of Medicine, USA
}

\begin{abstract}
Correspondence: Samuel A Nigro, Retired, Assistant Clinical Professor Psychiatry, Case Western Reserve University School of Medicine, 2517 Guilford Road, Cleveland Heights, Ohio
\end{abstract} 44I I8, USA, Tel (216) 932-0575, Email SAM@docnigro.com

Received: February 15, 2017| Published: February 20, 2017

make a cough more effective, do the SAM! First shut the mouth, and then inhale nasally as deeply as you can, and then really explode a mouth cough into your kerchief or elbow. That really should be done as personal health measure twice daily for 3 coughs after brushing your teeth each time. This cleans your lungs. If you feel a chest cold coming on, do it several more times whenever. It can help prevent the chest cold and can keep you healthier.

\section{Best knee \& back exercises}

Walk 50+ steps on your heels; or rock back and forth from one heel to the other. The paraspinal muscles (including the psoas) and hip ab \& ad -ductors are all tightened by walking on your heels. You will be surprised how the aches and pains often disappear after consistent heel walking (or rocking). The paraspinal muscles especially do not get exercised and it seems that the spinal cord system works better with stronger paraspinal muscles. I discovered this during my recovery from bilateral simultaneous knee replacements. It worked and I found heel walking helped whenever I have had knee or back aches ever since. Walking on heels is almost a full body massage of back related muscles we hardly ever use in daily routines. Easiest to do while brushing your teeth.

\section{Saving teeth}

This is my one time experience. Wisdom teeth extracted as young adult, so, at 78 years old, my lower left 2 nd molar begins to throb and hurt. The dentist checks with $\mathrm{x}$-rays finding nothing but recommends someone for extraction--"This is what is regularly done to relieve the pain and discomfort" (which I knew because of relatives' having many such extractions). However, the dentist did give me a trial of penicillin and higher fluoride toothpaste which did not work after two weeks. But I thought that the antibiotic by pills would never get concentrated about that tooth, so I bought topical triple antibiotic cream. I squeezed a little high fluoride toothpaste and the topical antibiotic on my finger and massaged them onto and around my hurting tooth. I did this after tooth brushing morning and night. My tooth cleared up and it has been 8 months with normal painless functioning. I still do the toothpaste/antibiotic massage every morning. It is merely one case, but it is so simple, inexpensive and it is still working! Perhaps it is 
worth trying. Studies show that simple dental cavities are due to infection--occasional antibiotic massage may be preventive of most dental problems.

Also, dental antibiotic massage might help reduce infections if on steroids for any reason. I was briefly put on steroids for traumatic arthritis and could feel an increase in dental sensitivity, so I started my topical antibiotic dental massage until off the steroids. This makes one consider the "preventive" aspects of topical antibiotic dental massage for infections if in a hospital or wherever there are high concentrations of infectuous disease agents--or a dab into each nostril and on ones gums at the first sign of a cold might help defense against full cold syndrome.

\section{Saving children's mental health}

Doc SAM presented interactional drawings with children as an effective therapy in child psychiatry and mental health promoting technique for parents and their children. This was a Grand Rounds Presentation, Department of Psychiatry, Case Western Reserve University School of Medicine: "Therapeutic Sequential Drawings with Children -- a New Technique" 1970. He extended D. W. Winnicott's "squiggles" by taking turns with the child in the creation of the drawings. This helped and led the child to express the good, the bad, the ugly, the helpful for "that week" or month or any time interval. Any past or anticipated event could be focused on by interactional mutual drawing with the child creating, and reliving, an emotive event. While drawing, the therapeutic emoting and processing were far beyond simple "talking it out." The words used while drawing have more intense, deeper and material substance to the catharsis. Reproductions of series of drawings were provided with the stories briefly detailed. The presentation was then submitted as an article for the Journal of Pediatric and Adolescent Psychiatry. A jealous and anti-Catholic supervisor prevented its publication. She graduated the same year as Doc SAM from medical school, but got to complete her psychiatric training while Doc SAM served four years in the U.S. Navy. That qualified her to supervise him during his psychiatric residency. The director of the Department of Child Psychiatry made her tell Doc SAM of her preventing his article's publication. Other reviewers of the Journal of Pediatric and Adolescent Psychiatry contacted him about his "Squiggles" article asking his support for their individual plans to promulgate such. Doc SAM believes that parents and others can do the Squiggle drawing effort with their children on a regular basis with great emotional benefit and positive interactional relationship enhancement. "Let's draw the best thing that happened this week". "Let's draw the worst thing that happened". "Let us draw-X- ("your emergency room visit!" for example). Doc SAM believes this is not only a therapeutic technique for physicians wanting to help a child work through emotions, but a universal mental health parenting technique helping positive child development and self understanding in the family setting. Universally, parents should do this with each child each week. Doc SAM believes this will improve all child development and family togetherness.

\section{Reducing obesity and other obsessions "Dis- tract from obsessions"}

By doing the SAM gently and repeatedly, when the urge hits to eat or do one's obsession, and repeating the Catholic Mantra of "life, sacrifice, virtue, love, humanity, peace, freedom, and death without fear" over and over, you may be able to gradually free yourself from your habituation/obsession. It takes time and practice but most can be helped by the extra oxygen of the SAM and the distraction of naming the ultimate human purposes.

\section{Stopping snoring}

Like Pavlov's dog, condition technique should work. Jostle the snorer shaking his shoulder. At the Same time say: "Shut your mouth (you can gently push his chin with other hand) and breathe through your nose only and roll over". Repeat until he does. In time, with repetition, he will likely be conditioned to do it all as soon as you put your hand on his shoulder. Snoring is from the mouth. With the mouth closed, there is no snoring. Breathing through the nose gets more oxygen and is healthier than mouth breathing.

\section{Acknowledgements}

None.

\section{Conflict of interest}

The author declares no conflict of interest. 